\title{
Awareness of glaucoma in the western region of Saudi Arabia
}

\author{
Nawaf Almarzouki ${ }^{1}$ \\ ${ }^{1}$ Department of Ophthalmology, King Abdulaziz University Hospital, Jeddah, Saudi Arabia
}

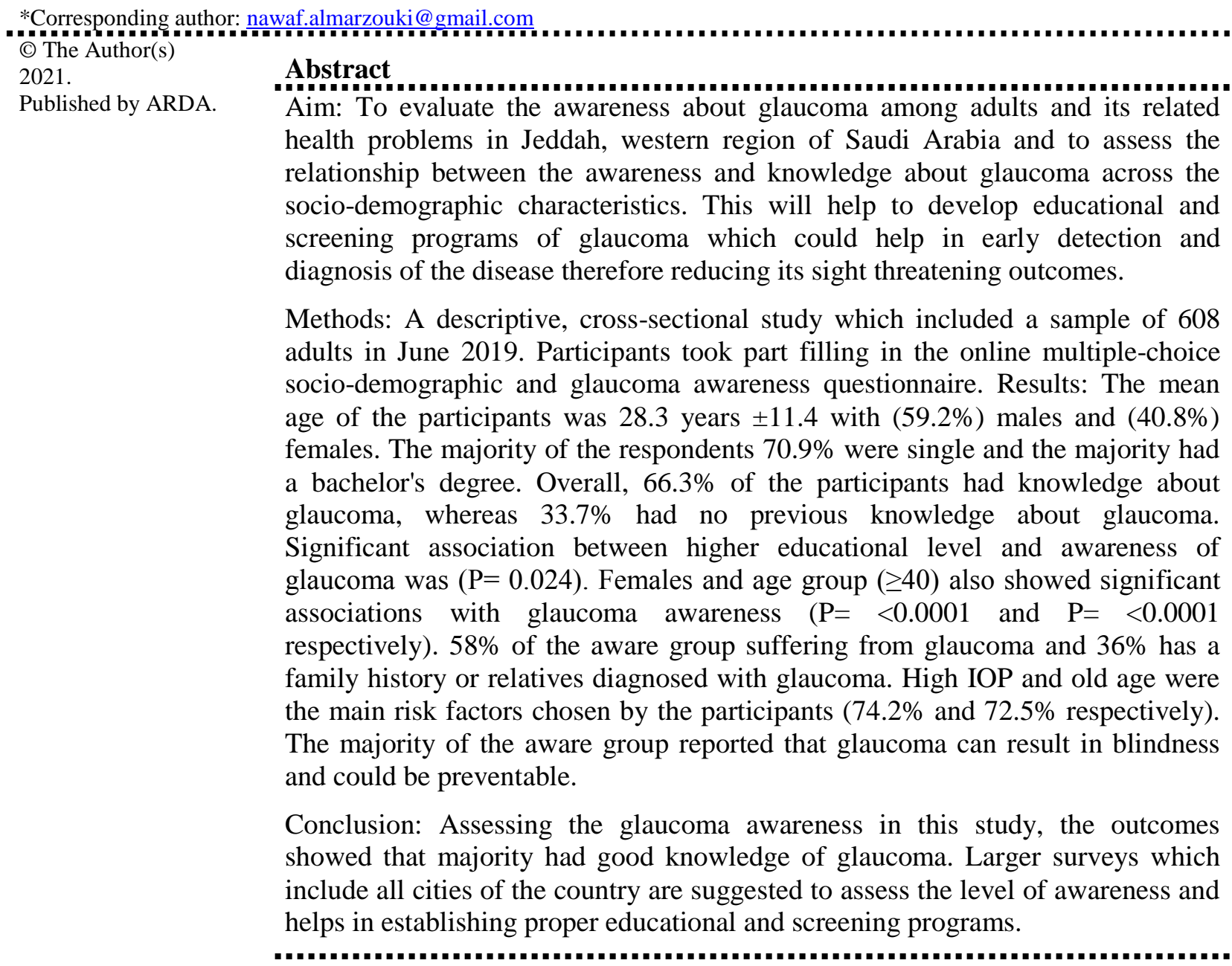

Keywords: Awareness, Glaucoma, Knowledge, Saudi Arabia

\section{Introduction}

Glaucoma is a condition affecting the optic nerve. It usually occurs when fluid builds up in the anterior chamber, which elevates the intraocular pressure (IOP) and damage the optic nerve [1]. Glaucoma progression is closely related to elevation in the IOP [2]. Furthermore, glaucoma is considered the second most common cause of bilateral blindness worldwide, representing $14 \%$ of the blind population [3-6]. Therefore, raising awareness about Glaucoma had become of a great importance.

Having "awareness" of glaucoma means that a person has a pervious knowledge about the disease or any proper understanding of the disease [7]. Being aware about glaucoma can increase the chance of identifying undetected cases, as glaucoma advances gradually, with few or no recognizable symptoms in the early stage $[7,8]$. This Mindfulness about glaucoma and other eye diseases, as well as the appropriate treatment and the

This work is licensed under a Creative Commons Attribution License (https://creativecommons.org/licenses/by/4.0/ ) that allows others to share and adapt the material for any purpose (even commercially), in any medium with an acknowledgement of the work's authorship and initial publication in this journal. 
need for regular follow-up with an eye care provider, can play a significant role in the prevention of irreversible visual impairment from eye diseases such as glaucoma $[5,9,10]$.

A study in Chennai, India, revealed that the level of awareness was generally low, and that highly educated people had more knowledge about glaucoma than did people with limited education [11]. In addition, a study done in Hyderabad, in southern India, to assess knowledge about eye diseases showed that awareness of cataract was $69.8 \%$, of night blindness was $60.0 \%$, and of diabetic retinopathy was $27.0 \%$, whereas awareness of glaucoma was very poor 2.3\% [12]. Moreover, a study done in Riyadh, Saudi Arabia, showed that knowledge of glaucoma was poor compared with knowledge of other eye problems [13]. However, few reports have been done in our region about chronic eye diseases, and glaucoma was the least disease to be aware of in comparison with other diseases [13]. Therefore, the aim of this study was to assess the awareness of glaucoma and its related health issues among adults in the western region of Saudi Arabia.

\section{Material and methods}

A descriptive, cross-sectional study took place at King Abdulaziz University Hospital (KAUH) in Jeddah, Saudi Arabia, in June 2019.The study was approved by the Ethics Committee at King Abdulaziz University Hospital. This study adhered to the tenets of the Declaration of Helsinki.

The study comprised of a sample size of 608 adults. Inclusion criteria were participants who were from Jeddah and at least 20 years of age. Participants completed Arabic, online self-report Google-form questionnaire, within which online consent was obtained. The questionnaire was composed of three sections of multiple-choice questions, all of which with single answer except single question about risk factors they could choose multiple answers, each question in the third section has (I don't know) answer. The first section contained questions regarding socio-demographic details, as follows: age, sex, marital status, education status, area of accommodation as which region and city in Kingdom of Saudi Arabia, in addition to a question about working in the medical field. The second section consisted of questions regarding awareness of glaucoma, and general and eye health. The third section included questions that assessed knowledge about glaucoma. This questionnaire was shared via WhatsApp, Twitter, and Telegram.

Data entry was performed using Google Sheet, and statistical analysis was performed with Statistical Package for the Social Sciences (IBM Corp. Released 2012. IBM SPSS Statistics for Windows, Version 21.0. Armonk, NY: IBM Corp) using chi-square tests.

\section{Results}

A total of 608 adults living in Jeddah were included in this study. The mean age of the participants was 28.3 years \pm 11.4 (range 20-77 years old). There were 360 (59.2\%) males and 248 (40.8\%) females. The majority of the respondents $70.9 \%$ were single, and most of them had at least a bachelor's degree. Only $33.2 \%$ of the respondents had worked, or were still working, in the medical field. Table 1 and Table 2 show the results of the research.

Table 1. Demographics

\begin{tabular}{lccc}
\hline & Variables & Frequency (n=608) & Percent (\%) \\
\hline Gender & Male & 360 & 59.2 \\
Educational Degree & Female & 248 & 40.8 \\
& less than high school & 5 & .8 \\
& high school & 182 & 29.9 \\
& diploma & 41 & 6.7 \\
Age Group & bachelor & 344 & 56.6 \\
& high educated & 36 & 5.9 \\
& $<40$ & 502 & 82.6 \\
& $\geq 40$ & 106 & 17.4 \\
\hline
\end{tabular}


Table 2. Awareness and knowledge about Glaucoma in comparison to age group and gender

\begin{tabular}{|c|c|c|c|c|c|c|c|}
\hline & \multirow[t]{2}{*}{ Total } & \multicolumn{2}{|c|}{ Gender } & \multirow[t]{2}{*}{ p value } & \multicolumn{2}{|c|}{ Age Group } & \multirow[t]{2}{*}{ P value } \\
\hline & & Male & Female & & $<40$ & $\geq 40$ & \\
\hline Have you ever heard of glaucoma? (yes) & 403 & $211(52.4 \%)$ & $192(47.6 \%)$ & $<0.0001$ & $314(77.9 \%)$ & $89(22.1 \%)$ & $<0.0001$ \\
\hline $\begin{array}{l}\text { Where did you first hear about glaucoma } \\
\text { (News Media) }\end{array}$ & 181 & $91(50.3 \%)$ & $90(49.7 \%)$ & 0.512 & $128(70.7 \%)$ & $53(29.3 \%)$ & $<0.05$ \\
\hline $\begin{array}{l}\text { Where did you first hear about glaucoma } \\
\text { (Brochures/ posters) }\end{array}$ & 83 & $47(56.6 \%)$ & $36(43.4 \%)$ & 0.453 & $59(71.1 \%)$ & $24(28.9 \%)$ & 0.124 \\
\hline Where did you first hear about glaucoma & 82 & $41(50 \%)$ & $41(50)$ & 0.723 & $69(84.1 \%)$ & $13(15.9 \%)$ & 0.169 \\
\hline $\begin{array}{l}\text { Where did you first hear about glaucoma } \\
\text { (health workers) }\end{array}$ & 215 & $124(57.7 \%)$ & $91(42.3 \%)$ & $<0.05$ & $190(88.4 \%)$ & $25(11.6 \%)$ & $<0.001$ \\
\hline $\begin{array}{l}\text { Where did you first hear about glaucoma } \\
\text { (People with glaucoma) }\end{array}$ & 234 & $109(46.6 \%)$ & $125(53.4 \%)$ & $<0.05$ & $173(73.9 \%)$ & $61(26.1 \%)$ & $<0.05$ \\
\hline $\begin{array}{l}\text { How would you explain glaucoma? (High } \\
\text { eye pressure damaging eye) }\end{array}$ & 200 & $98(49 \%)$ & $102(51 \%)$ & 0.606 & $174(87 \%)$ & $26(13 \%)$ & $<0.0001$ \\
\hline $\begin{array}{l}\text { How would you explain glaucoma? (Causes } \\
\text { damage to the eye nerve) }\end{array}$ & 38 & $21(55.3 \%)$ & $17(44.7 \%)$ & 0.606 & $31(81.6 \%)$ & $7(18.4 \%)$ & $<0.0001$ \\
\hline $\begin{array}{l}\text { How would you explain glaucoma? } \\
\text { (Causing visual field loss) }\end{array}$ & 123 & $68(55.3 \%)$ & $55(44.7 \%)$ & 0.606 & $81(65.9 \%)$ & $42(34.1 \%)$ & $<0.0001$ \\
\hline Do you have family member with & 147 & $64(43.5 \%)$ & $83(56.5 \%)$ & $<0.05$ & $108(73.5 \%)$ & $39(26.5 \%)$ & 0.121 \\
\hline Have you examined your eyes? (yes) & 348 & $194(55.7 \%)$ & $154(45.3 \%)$ & 0.054 & $277(79.6 \%)$ & $71(20.4 \%)$ & $<0.05$ \\
\hline Do you have glaucoma? (yes) & 11 & $6(54.5 \%)$ & $5(45.5 \%)$ & 0.0001 & $6(54.5 \%)$ & $5(45.5 \%)$ & $<0.05$ \\
\hline Do you have hypertension currently? (yes) & 37 & $22(59.5 \%)$ & $15(40.5 \%)$ & 0.111 & $15(40.5 \%)$ & $22(59.5 \%)$ & $<0.0001$ \\
\hline Do you have diabetes mellitus currently? & 25 & $14(56 \%)$ & $11(44 \%)$ & 0.315 & $7(28 \%)$ & $18(72 \%)$ & $<0.0001$ \\
\hline Can glaucoma occur without symptom? & 131 & $74(56.5 \%)$ & $57(43.5 \%)$ & 0.061 & $102(77.9 \%)$ & $29(22.1 \%)$ & 0.187 \\
\hline $\begin{array}{l}\text { What are the risk factors for glaucoma? } \\
\text { (High eye pressure) }\end{array}$ & 361 & $187(51.8 \%)$ & $174(48.2 \%)$ & $<0.0001$ & $294(81.4 \%)$ & $67(18.6 \%)$ & 0.708 \\
\hline What are the risk factors for glaucoma? & 357 & $189(52.9 \%)$ & $168(47.1 \%)$ & $<0.0001$ & $283(79.3 \%)$ & $74(20.7 \%)$ & $<0.05$ \\
\hline $\begin{array}{l}\text { What are the risk factors for glaucoma? } \\
\text { (Family history of glaucoma) }\end{array}$ & 267 & $134(50.2 \%)$ & $133(49.8 \%)$ & $<0.0001$ & $213(79.8 \%)$ & $54(20.2 \%)$ & 0.272 \\
\hline What are the risk factors for glaucoma? & 122 & $71(58.2 \%)$ & $51(41.8 \%)$ & 0.176 & $107(87.7 \%)$ & $15(12.3 \%)$ & 0.244 \\
\hline $\begin{array}{l}\text { What are the risk factors for glaucoma? } \\
\text { (Black race) }\end{array}$ & 37 & $18(48.6 \%)$ & $19(51.4 \%)$ & $<0.05$ & $32(86.5 \%)$ & $5(13.5 \%)$ & 0.685 \\
\hline $\begin{array}{l}\text { What are the risk factors for glaucoma? } \\
\text { (Steroid usage) }\end{array}$ & 100 & $53(53 \%)$ & $47(47 \%)$ & 0.356 & $91(91 \%)$ & $9(9 \%)$ & $<0.05$ \\
\hline Is blindness from glaucoma preventable? & 301 & $163(54.2 \%)$ & $138(45.8 \%)$ & $<0.05$ & $244(81.1 \%)$ & $57(18.9 \%)$ & 0.644 \\
\hline Is glaucoma curable? (yes) & 238 & $139(58.4 \%)$ & $99(41.6 \%)$ & 0.109 & $184(77.3 \%)$ & $54(22.7 \%)$ & $<0.001$ \\
\hline $\begin{array}{l}\text { When does glaucoma affect vision? (As } \\
\text { soon as it starts) }\end{array}$ & 50 & $22(44 \%)$ & $28(56 \%)$ & $<0.001$ & $32(64 \%)$ & $18(36 \%)$ & $<0.001$ \\
\hline $\begin{array}{l}\text { When does glaucoma affect vision? (In the } \\
\text { late stage) }\end{array}$ & 299 & $149(49.8 \%)$ & $150(50.2 \%)$ & $<0.001$ & $242(80.9 \%)$ & $57(19.1 \%)$ & $<0.001$ \\
\hline Can glaucoma cause blindness? (yes) & 352 & $182(51.7 \%)$ & $170(48.3 \%)$ & 0.0001 & $284(80.7 \%)$ & $68(19.3 \%)$ & 0.375 \\
\hline Is glaucoma treatable? (yes) & 394 & $209(53 \%)$ & $185(47 \%)$ & 0.0001 & $315(79.9 \%)$ & $79(20.1 \%)$ & 0.054 \\
\hline $\begin{array}{l}\text { What treatments do you know? (Medicines } \\
\text { - eye drops) }\end{array}$ & 242 & $124(50 \%)$ & $124(50 \%)$ & $<0.05$ & $212(85.5 \%)$ & $36(14.5 \%)$ & $<0.05$ \\
\hline What treatments do you know? (Surgery) & 334 & $180(53.9 \%)$ & $154(46.1 \%)$ & $<0.05$ & $262(78.4 \%)$ & $72(21.6 \%)$ & $<0.05$ \\
\hline $\begin{array}{l}\text { What treatments do you know? } \\
\text { (Radiation/laser) }\end{array}$ & 220 & $115(52.3 \%)$ & $105(47.7 \%)$ & $<0.05$ & $181(82.3 \%)$ & $39(17.7 \%)$ & 0.867 \\
\hline $\begin{array}{l}\text { What is the purpose glaucoma treatment? } \\
\text { (To restore vision) }\end{array}$ & 229 & $126(55 \%)$ & $103(45 \%)$ & $<0.0001$ & $178(77.7 \%)$ & $51(22.3 \%)$ & $<0.05$ \\
\hline $\begin{array}{l}\text { What is the purpose glaucoma treatment? } \\
\text { (To delay progression) }\end{array}$ & 161 & $76(47.2 \%)$ & $85(52.8 \%)$ & $<0.001$ & $129(80.1 \%)$ & $32(19.9 \%)$ & $<0.05$ \\
\hline $\begin{array}{l}\text { Is glaucoma damage reversible via } \\
\text { treatment? (yes) }\end{array}$ & 199 & $101(50.8 \%)$ & $98(49.2 \%)$ & $<0.05$ & $155(77.9 \%)$ & $44(22.1 \%)$ & $<0.05$ \\
\hline Is glaucoma heritable from families? (yes) & 132 & $57(43.2 \%)$ & $75(56.8 \%)$ & $<0.0001$ & $106(80.3 \%)$ & $26(19.7 \%)$ & 0.624 \\
\hline Are you at risk of glaucoma? (yes) & 42 & $20(47.6 \%)$ & $22(52.4 \%)$ & $<0.05$ & $27(64.3 \%)$ & $15(35.7 \%)$ & $<0.05$ \\
\hline
\end{tabular}

Overall, $66.3 \%$ of the participants had knowledge about glaucoma, whereas $33.7 \%$ had no information about glaucoma. The relationship between education level (higher education) and awareness of glaucoma was significant $(\mathrm{P}=0.024)$. Participant sex (Female), and age group $(\geq 40)$ also showed significant associations with glaucoma awareness $(\mathrm{P}=<0.0001$ and $\mathrm{P}=<0.0001$ respectively). 
The most common source of information for these respondents was patients suffering from glaucoma, at a total of 58\%. Moreover, $36 \%$ of the total respondents have a family history or relatives diagnosed with glaucoma. Additionally, $57.2 \%$ underwent regular eye check exams.

Considering those who reported being aware of glaucoma $(n=403), 74.2 \%$ of the participants considered high IOP to be a risk factor for glaucoma, followed by old age (72.5\%). Conversely, only $6.5 \%$ considered being of black race to be a risk factor. Regarding potential vision loss, $76.2 \%$ of the aware participants reported that glaucoma could eventually cause blindness. More than half of the aware participants $64 \%$ believed blindness could be preventable; only $4 \%$ believe it is not preventable. In addition, $48.6 \%$ indicated that glaucoma is curable, with $14.9 \%$ saying it is not curable, and 36.5\% not knowing the answer. Moreover, $81.4 \%$ reported that glaucoma is a treatable disease, and $1.7 \%$ not treatable; the remaining $16.9 \%$ did not know the answer. Considering the treatment options, the majority of the aware participants cited surgery, followed by eye drops; laser treatment came last. The study also found that $44.9 \%$ of the aware respondents believed that the purpose of treatment is to regain vision, $35.2 \%$ believed that the purpose is to delay the progress of the disease, whereas the remaining $19.9 \%$ did not know the answer.

\section{Discussion}

This cross-sectional study aimed to determine the level of awareness and knowledge regarding glaucoma among the adult population in western region of Saudi Arabia which enrolled 608 participants. The level of awareness about glaucoma was relatively high in the study group. In total, $66.3 \%$ of the respondents were aware of glaucoma which is consistent with Alnujaim et al 2018 study from Riyadh, where $64 \%$ of the study participants were aware of glaucoma [2]. Our findings also resemble Al-Lahim et al 2018 report in Tabuk, northwestern of Saudi Arabia, in which $67.5 \%$ of participants had a knowledge of the disease [14].Moreover, in other international studies, , $65.5 \%$ of a study sample in Southeast Nigeria demonstrated a high level of awareness [15]. An Australian study in 1997 revealed a very high awareness level (93\%), However, other surveys in Switzerland 2006, India 2001, and Ethiopia 2010, showed that the levels of awareness were low $(24.7 \%, 2.4 \%$ and $2.3 \%$, respectively) $[9,12,16,17]$. This variation might be due to differences in education level, age, and socioeconomic status.

There was a significant association between awareness of glaucoma and other variables, such as age group, gender, and educational level in this study. These associations with respect to age and educational level are consistent with Alnujaim et al study from Riyadh [2]. Conversely, Al-Lahim et al 2018 study in Tabuk revealed that only education level to be significant [14]. Moreover, Mansouri et al2006 study in Switzerland did not find any relationship between demographic characteristics and the level of awareness of glaucoma [9]. Variation in the demographic characteristics in the study samples may contribute to these differences in results. The primary source of participants' knowledge regarding glaucoma in the study was people suffering from glaucoma (58\%). This parallels the results of Rewri and Kakkar's study in rural India [18], but differs from several studies, in which the participants selected an ophthalmologist $(69 \%)$, the internet (46\%), or mass media $(35.4 \%)$ as their source of information $[9,17,18]$. This particular result in the study could be due to a high incidence of glaucoma or diabetes in Saudi Arabia; diabetes is a possible predecessor to glaucoma, which might lead to a high rate of exposure to people with glaucoma.

Based on the questionnaire answers in this study, we have demonstrated a good knowledge (66.3\%) about glaucoma generally. This agrees with Alnujaim et al 2018 study from Riyadh which showed a high level of knowledge, as well as Nkum et al.'s study done in Ghana in 2015 [2,19]. On the contrary, Attebo et al.'s study, done in Australia, showed that only $29 \%$ had knowledge of glaucoma, and only $27 \%$ of the participants had sufficient knowledge about glaucoma in Nkum et al.'s study [16,19]. The high level of knowledge in the present study could be attributed to campaigns organized by the Saudi Ministry of Health and medical faculties through seminars, workshops and social media which targeted people in hospitals and other public places like shopping malls and social events which in turn rises the knowledge about Glaucoma. Limitations of this study are a high percentage of the participants were from a young age group.

\section{Conclusion}

When evaluating the glaucoma awareness in this study, the outcomes showed that majority had good knowledge of glaucoma with only a few having excellent knowledge. Larger surveys which include all cities of the country are suggested to assess the level of awareness and helps in establishing proper educational and screening campaigns. 


\section{References}

[1] Weinreb, Robert N, and Peng Tee Khaw. "Primary open-angle glaucoma." Lancet (London, England) vol. 363, no. 9422, pp.1711-1720, 2004. doi:10.1016/S0140-6736(04)16257-0.

[2] Nujaim H etal. "Awareness and knowledge of glaucoma among the general Saudi public". IAIM, vol. 5, no 1, pp.107-110, 2018.

[3] Resnikoff, Serge et al. "Global data on visual impairment in the year 2002." Bulletin of the World Health Organization vol. 82, no. 11 pp.844-851, 2004.

[4] Friedman, David S et al. "Prevalence of open-angle glaucoma among adults in the United States." Archives of ophthalmology (Chicago, Ill. : 1960) vol. 122, no. 4, pp.532-538, 2004. doi:10.1001/archopht.122.4.53.

[5] Hark, Lisa A et al. "Awareness of ocular diagnosis, transportation means, and barriers to ophthalmology follow-up in the Philadelphia Telemedicine Glaucoma Detection and Follow-up Study." Social work in health care vol. 58, no. 7, pp. 651-664, 2019. doi:10.1080/00981389.2019.1614711.

[6] Parihar, J K S. "Glaucoma: The 'Black hole' of irreversible blindness." Medical journal, Armed Forces India vol. 72, no. 1, pp.3-4. 2016. doi:10.1016/j.mjafi.2015.12.001.

[7] Komolafe, $\mathrm{O} \mathrm{O}$ et al. "Awareness and knowledge of glaucoma among workers in a Nigerian tertiary health care institution." Middle East African journal of ophthalmology vol. 20, no. 2, pp.163-167, 2013. doi:10.4103/0974-9233.110609

[8] Gasch, A T et al. "Determinants of glaucoma awareness in a general eye clinic." Ophthalmology vol. 107, no. 2, pp. 303-308, 2000. doi:10.1016/s0161-6420(99)00076-7

[9] Mansouri, Kaweh et al. "Awareness about glaucoma and related eye health attitudes in Switzerland: a survey of the general public." Ophthalmologica. Journal international d'ophtalmologie. International journal of ophthalmology. Zeitschrift fur Augenheilkunde, vol. 220, no. 2, pp. 101-108, 2006.

[10] Dutta, M. K. et al. "Glaucoma detection by segmenting the super pixels from fundus colour retinal images." 2014 International Conference on Medical Imaging, m-Health and Emerging Communication Systems (MedCom), pp. 86-90, 2014.

[11] Sathyamangalam, Ramesh Ve et al. "Determinants of glaucoma awareness and knowledge in urban Chennai." Indian journal of ophthalmology vol. 57, no. 5, pp.355-360, 2009.

[12] Dandona, R et al. "Awareness of eye diseases in an urban population in southern India." Bulletin of the World Health Organization vol. 79, no. 2, pp.96-102, 2001.

[13] Al Rashed, Waleed A et al. "Public Awareness regarding Common Eye Diseases among Saudi Adults in Riyadh City: A Quantitative Study.” Journal of ophthalmology vol. 2017, 9080791. doi:10.1155/2017/9080791.

[14] Al-Lahim W et al. "Evaluation of Awareness and Attitudes towards Common Eye Diseases among the General Population of Northwestern Saudi Arabia". The Egyptian Journal of Hospital Medicine, vol. 70, no. 11, pp.1983-1989, 2018. doi: 10.12816/ejhm.2018.9403.

[15] Kizor-Akaraiwe, Nkiru $\mathrm{N}$ et al. "Awareness and knowledge about glaucoma and proportion of people with glaucoma in an urban outreach programme in Southeast Nigeria." BMJ open ophthalmology vol. 1, no 1, e000018. 7 Mar. 2017, doi:10.1136/bmjophth-2016-000018.

[16] Attebo, $\mathrm{K}$ et al. "Knowledge and beliefs about common eye diseases." Australian and New Zealand journal of ophthalmology vol. 25, no. 4, pp.283-287, 1997. doi:10.1111/j.1442-9071.1997.tb01516.x

[17] Tenkir, A et al. "Glaucoma awareness among people attending ophthalmic outreach services in Southwestern Ethiopia”. BMC Ophthalmol vol. 10, no. 17, 2010. doi.org/10.1186/1471-2415-10-17.

[18] Rewri, Parveen, and Mukesh Kakkar. "Awareness, knowledge, and practice: a survey of glaucoma in north Indian rural residents." Indian journal of ophthalmology, vol. 62, no. 4, pp.482-486, 2014. doi:10.4103/0301-4738.132105.

[19] Nkum, G et al. "Awareness and Knowledge of Glaucoma Among Adult Patients at the Eye Clinic of a Teaching Hospital." Ghana medical journal vol. 49, no. 3, pp.195-199, 2015. doi:10.4314/gmj.v49i3.11 